\title{
A retrospective study of two populations to test a simple rule for spirometry
}

\author{
Jill A. Ohar ${ }^{1 *}$, Barbara P. Yawn ${ }^{2}$, Gregg L. Ruppel ${ }^{3}$ and James F. Donohue ${ }^{4}$
}

\begin{abstract}
Background: Chronic lung disease is common and often under-diagnosed.

Methods: To test a simple rule for conducting spirometry we reviewed spirograms from two populations, occupational medicine evaluations (OME) conducted by Saint Louis and Wake Forest Universities at 3 sites ( $n=3260$, mean age 64.14 years, $95 \% \mathrm{Cl}$ 58.94-69.34, $97 \%$ men) and conducted by Wake Forest University preop clinic (POC) at one site ( $n=845$, mean age 62.10 years, $95 \% \mathrm{Cl} 50.46-73.74,57 \%$ men). This retrospective review of database information that the first author collected prospectively identified rates, types, sensitivity, specificity and positive and negative predictive value for lung function abnormalities and associated mortality rate found when conducting spirometry based on the 20/40 rule ( $\geq 20$ years of smoking in those aged $\geq 40$ years) in the OME population. To determine the reproducibility of the 20/40 rule for conducting spirometry, the rule was applied to the POC population.

Results: A lung function abnormality was found in $74 \%$ of the OME population and $67 \%$ of the POC population. Sensitivity of the rule was $85 \%$ for an obstructive pattern and $77 \%$ for any abnormality on spirometry. Positive and negative predictive values of the rule for a spirometric abnormality were 74 and $55 \%$, respectively. Patients with an obstructive pattern were at greater risk of coronary heart disease (odds ratio (OR) 1.39 [confidence interval (CI) 1.00-1. 93] vs. normal) and death (hazard ratio (HR) 1.53, $95 \%$ Cl 1.20-1.84) than subjects with normal spirometry. Restricted spirometry patterns were also associated with greater risk of coronary disease (odds ratio (OR) 1.7 [Cl 1.23-2.35]) and death (Hazard ratio 1.40, $95 \% \mathrm{Cl}$ 1.08-1.72).
\end{abstract}

Conclusions: Smokers ( $\geq 20$ pack years) age $\geq 40$ years are at an increased risk for lung function abnormalities and those abnormalities are associated with greater presence of coronary heart disease and increased all-cause mortality. Use of the 20/40 rule could provide a simple method to enhance selection of candidates for spirometry evaluation in the primary care setting.

Keywords: COPD, Spirometry, Smoking, Respiratory symptoms

\section{Background}

Spirometry is an important tool for assessing lung function and the development of mobile, accurate and less expensive equipment has allowed the assessment of spirometry in primary care settings [1-3]. However, spirometry testing remains underutilized in primary care $[4,5]$, perhaps due to the lack of clarity of when to use spirometry evaluation. Universal spirometry screening has been assessed for improved Chronic Obstructive Pulmonary Disease (COPD) diagnoses and found to be too expensive, requiring testing of up to 465 individuals to deter one COPD

\footnotetext{
* Correspondence: johar@wakehealth.edu

'Department of Internal Medicine, Wake Forest School of Medicine, Medical

Center Boulevard, Winston-Salem, NC 27157-1054, USA

Full list of author information is available at the end of the article
}

exacerbation [6]. Guidance is required to select an appropriate subset of the general population in whom to complete spirometry testing.

But smokers are at increased risk for a variety of abnormalities of lung function, not just COPD and lung function abnormalities have been reported in more than half of current smokers [7]. Risk for, and under-detection of, pulmonary function abnormalities, increase with increasing age [8]. Pulmonary function abnormalities are markers for increased morbidity and mortality [8-15]. Despite this association pulmonary function abnormalities frequently go undetected in clinical practice $[4,16-18]$.

Selective use of spirometry has been directed primarily toward identification of individuals with undiagnosed 
COPD. For example, Global Initiative for Chronic Obstructive Lung Disease (GOLD) suggests spirometric testing for COPD identification based on age $>40$ years and risks, such as smoking history, or symptoms [19]. The American College of Physicians recommends testing based on presence of both smoking history and symptoms, such as cough, dyspnea, or wheeze, for testing [20]. This requires collection of new clinical information that may not be in the existing medical records nor volunteered by the patient.

Conversely, all medical records should include the patient's age and smoking status. We present data on the use of a simple rule that includes only the patient's age and smoking history to determine the need for spirometry to detect lung abnormalities including those beyond the obstructive patterns most consistent with COPD. In addition, we assess the mortality risk associated with the identified lung abnormalities [8-13].

\section{Methods}

\section{Study populations}

The OME group included workers screened for occupation lung disease conducted by Saint Louis and Wake Forest Universities at 3 sites. Details of a portion of this population have been reported previously [21]. Criteria for occupational medical evaluation (OME) was occupational exposure to asbestos that was at least 10 years prior to evaluation and the possibility of an abnormal chest $\mathrm{x}$-ray (i.e., the presence of pleural plaque or International Labor Union scoring of $0 / 1$ or above). Data came from retrospective review of clinical data and pulmonary function testing acquired 1983-2010 that was housed in a data repository. Only subjects with a complete set of data were used. All individuals had a brief history, chest radiograph and pulmonary function testing. The history included asking subjects if a healthcare professional had ever given them a diagnosis of chronic obstructive pulmonary disease, asthma, or heart disease including angina, myocardial infarction or coronary heart disease. Subjects were included in the analysis regardless of whether they were previously diagnosed with COPD, asthma or not. Details of the reliability of symptoms and clinical diagnosis of COPD in a portion of this population have previously been published (21). Cigarette smoking history (never, former or current) was further quantified by pack-years and a chest radiograph was completed for each patient. Based on published chronic obstructive pulmonary disease demographics [22], enrollment was limited to individuals age $\geq 40$ years without evidence of significant work related chest $\mathrm{x}$-ray abnormalities. This protocol was reviewed and approved by the Saint Louis University and Wake Forest University Institutional Review Boards (IRB) prior to the initiation of the study.

To determine the reproducibility of the 20/40 rule for conducting spirometry, the rule was applied to a population of current or former smokers, 40 years of age and older, who had smoked 20 or more pack years, seen in the preoperative clinic (POC) before elective surgery, at Wake Forest University Baptist Medical Center. Subjects were evaluated with spirometry from October 2013 to July 2014.

\section{Pulmonary function testing}

Pulmonary function testing was performed by respiratory therapists and a registered nurse, according to ATS guidelines [23]. Spirometers (a Collins CPL at the 2 Wake Forest OME sites, Medgraphics at the Wake Forest POC site and a Puritan Bennett Renaissance at the Saint Louis University OME site) were all calibrated daily. All forced vital capacity (FVC) maneuvers lasting less than six seconds were discarded. Spirometric data were expressed as percent predicted using National Health and Nutrition Examination Survey (NHANES) III predicted equations [24]. Airflow obstruction was defined as a ratio of pre-bronchodilator $\mathrm{FEV}_{1} / \mathrm{FVC}<70 \%$ (forced expiratory volume in one second/forced vital capacity) derived from modification of National Institute for Clinical Excellence (NICE) [25] and Global Initiative for Chronic Obstructive Lung Disease (GOLD) recommendations necessary since post-bronchodilator testing was not available [26]. Spirometry was classified into four patterns according to the following definitions:

- Normal - $\mathrm{FEV}_{1} / \mathrm{FVC} \geq 70 \%$ and $\mathrm{FEV}_{1}>80 \%$ and $\mathrm{FVC}>80 \%$

- Obstructed - $\mathrm{FEV}_{1} / \mathrm{FVC}<70 \%$ and $\mathrm{FEV}_{1} \leq 80 \%$

- Restricted - $\mathrm{FEV}_{1} / \mathrm{FVC} \geq 70 \%$ and $\mathrm{FVC} \leq 80 \%$

- Unclassified - all others

\section{Coronary heart disease history}

Subjects from the OME population were asked if they had a history of a myocardial infarction, coronary artery stent, percutaneous transluminal coronary angioplasty (PTCA), or coronary artery bypass grafting. An affirmative response was considered positive evidence for selfreported coronary heart disease. Odds ratio for coronary heart disease was calculated by logistic regression.

\section{Survival}

Date of death for subjects from the OME group was determined through a search of the social security death database as of May 2012. Subjects not appearing on the social security death database were assumed to be alive. An adjusted survival analysis (Cox Proportional Hazards regression) was run on the deceased subset. Data was adjusted for age at the time of spirometric testing, coronary heart disease, asthma, COPD and smoking status (current, former or never). 


\section{Statistical measures}

Participant characteristics were compared across spirometry groups (normal, obstructed, and restricted) using either chi-square tests of association or one-way Analysis of Variance (ANOVA), as appropriate. Sensitivity, specificity, positive and negative predictive values and ROC curve were determined. All analyses were completed using SAS version 9.2 (SAS Institute, Inc., Cary, NC). Bonferroni corrections were made for multiple statistical testing. A $p$ value of 0.05 or less was considered statistically significant.

\section{Availability of data and materials}

According to the terms of approval of the Wake Forest University IRB, data can be published without written expressed consent from patients, if it is published in an aggregated form, without patient identifiers. However, if each patient's data is to be shared publicly, there is the possibility of patient identification and would warrant a signed informed consent. Unique patient data is therefore not available in a publicly accessible repository.

\section{Results}

Prevalence of spirographic abnormalities when applying the 20/40 algorithm

In the OME group, spirograms were performed on individuals 40 years of age and older $(n=3260) ; 2222$ individuals met algorithm criteria of $\geq 40$ years of age and smoking history of at least 20 pack/years (Fig. 1). Of the 2222 spirograms that met ATS criteria for evaluation, 174 fell into the unclassified category. Of the remaining 2048 spirograms in this population, 815 (39.8\%) were consistent with an obstructed pattern, 701 (34.2\%) with a restrictive pattern, and $532(26.0 \%)$ were normal. Age, pack-years smoked, and body mass index (BMI) all differed significantly among the individuals in the three

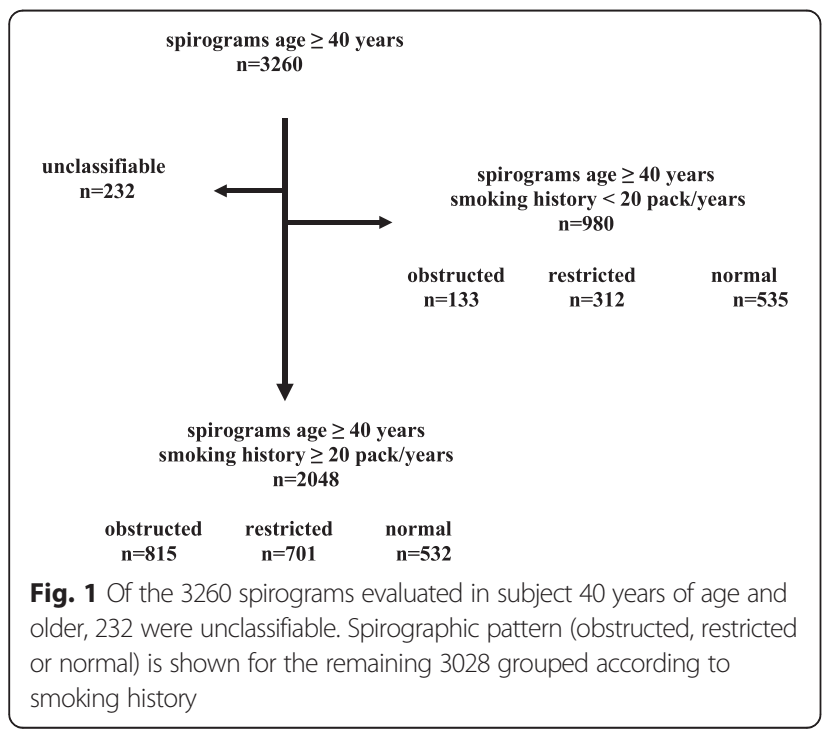

spirometric groups (Table 1). In general, the obstructed group was the oldest, had the highest rate of pack years of smoking, and was most likely to be current smokers with the restrictive group intermediate and the group with normal spirometry being the youngest and with the fewest pack years. The pattern for the BMI was slightly different with the highest average BMI in the restrictive group and the lowest in the obstructive group with those having normal spirometry intermediate. There was no significant difference in gender among the three groups, but men dominated the cohort by virtue of the method of recruitment.

\section{Self-reported coronary heart disease in subjects with abnormal spirometry (obstruction versus restriction)}

The prevalence of self-reported coronary heart disease was greater (chi-square, $p<0.0002$ ) in both the restricted $(20.5 \%)$ and obstructed (17.9\%) groups, compared to the normal spirometry group (12.0\%). Adjusting for BMI, smoking in pack years and age the odds ratio (OR) for having, self-reported coronary heart disease was significantly greater for individuals with restrictive (OR 1.70, $95 \%$ confidence interval 1.23-2.35) and individuals with obstructive (OR1.39, $95 \%$ confidence interval $1.00-1.93)$ spirometry patterns compared to those with normal spirometry. There was no significant difference in probability of coronary heart disease in the individuals with obstructive patterns compared to those with restrictive patterns, OR $1.22(0.93-1.60)$.

\section{Survival of subjects with abnormal spirometry}

Of the 2048 individuals available for analysis, e.g., those having obstructive or restrictive or normal spirometry patterns; 998 (48.7 \%) died. Survival was significantly different between those with normal and abnormal spirometry patterns but not between those with the restrictive and the obstructive patterns. The hazard ratio (HR) for death for the restrictive pattern group (compared to the normal group) was 1.40, $95 \%$ CI 1.08-1.72, indicating that the restricted group was at a $39.5 \%$ higher risk of death than the normal group. Similarly, the HR for the obstructive pattern group was $1.53,95 \%$ CI $1.20-1.84$ indicating a $52.7 \%$ greater risk of death than the normal group.

\section{Symptoms and self-report of obstructive lung disease}

There was a significant difference in reporting of respiratory symptoms among the three groups (Table 2). Subjects in the obstructive pattern group reported the highest rates of wheeze, cough, shortness of breath, and sputum production followed by those in the restrictive pattern group and then those with normal spirometry $(p<0.001)$.

Based on self-report, among those patients with an obstructive spirometry pattern, $37.3 \%$ had received a diagnosis of COPD alone with a further $9.5 \%$ reporting a 
Table 1 Subject characteristics - Occupational medical evaluation group

\begin{tabular}{|c|c|c|c|c|}
\hline & $\begin{array}{l}\text { Normal } \\
(n=532)\end{array}$ & $\begin{array}{l}\text { Obstructed } \\
(n=815)\end{array}$ & $\begin{array}{l}\text { Restricted } \\
(n=701)\end{array}$ & Significance \\
\hline $\mathrm{FEV}_{1} \%$ predicted [mean (SD)] & $94.3(8.8)$ & $53.6(16.3)$ & $70.7(11.6)$ & $P<0.001$ \\
\hline FVC \% predicted [mean (SD)] & $92.4(8.5)$ & $70.4(15.7)$ & $67.7(10.5)$ & $P<0.001$ \\
\hline $\mathrm{FEV}_{1} / \mathrm{FVC}[$ mean $(\mathrm{SD})]$ & $77.0(4.4)$ & $56.3(10.6)$ & $78.3(5.5)$ & $P<0.001$ \\
\hline Gender [n (\%) Male] & $513(99.4)$ & $795(97.6)$ & $674(96.2)$ & 0.1646 \\
\hline Current smoker [n (\%)] & $129(24.3)$ & $269(33.0)$ & $189(27.0)$ & $P<0.001$ \\
\hline Obesity [n (\%)] & $191(35.9)$ & $211(25.9)$ & $339(48.4)$ & $P<0.001$ \\
\hline BMI [mean (SD)] & $29.3(4.4)$ & $27.9(5.0)$ & $30.5(5.1)$ & $P<0.001$ \\
\hline Age [mean (SD)] & $62.0(9.1)$ & $65.8(8.5)$ & $64.2(9.2)$ & $P<0.001$ \\
\hline Pack years [mean (SD)] & $46.0(24.9)$ & $58.8(30.7)$ & $51.9(27.8)$ & $P<0.001$ \\
\hline
\end{tabular}

diagnosis of asthma and COPD, now labeled as ACOS (asthma-COPD overlap syndrome) [27] and $16.6 \%$ reporting a diagnosis of asthma alone. A COPD diagnosis was also reported by $19.1 \%$ of those with a restrictive spirometry pattern and by $11.3 \%$ of those with a normal spirometry result.

\section{Sensitivity, specificity, positive and negative predictive value}

The 20/40 rule was highly sensitive for obstructed spirometry with $86 \%$ (95\% confidence interval 84-88\%) sensitivity (Table 3). Sensitivity of the algorithm for any spirometric abnormality (either obstructive or restrictive) was $77 \%$ (confidence interval 75-79\%) The algorithm had a positive predictive value for any abnormality (either obstructive or restrictive) of $74 \%$ (confidence interval $72-80 \%$ ).

\section{0/40 rule replication}

There were 845 spirograms performed in the POC group. 98 failed to have three replicate loops greater than six seconds, and 74 were unclassifiable, based on our operational definitions, leaving 673 (79.6 \%) for interpretation. Despite the addition of women in the POC group compared with the OME group, and a higher percent of current smokers, the percent of abnormal spirograms was similar in the POC group compared with the OME group (Table 4). Sixty-seven percent were abnormal, $38.3 \%$ (258) with obstructive patterns, $28.4 \%$ (191) with restrictive patterns, and $33.3 \%$ (224) with normal spirometry.

\section{Discussion \\ Main findings}

Using a simple 20/40 rule based solely on age and smoking history identifies a high percent of individuals (74\% in the initial population and $67 \%$ in the POC group) with lung function abnormalities (both obstructive and restrictive spirometry patterns). Further those meeting the 20/40 rule who have lung function abnormalities have an increased risk of all-cause mortality and a high rate of reported coronary heart disease, compared to individuals with normal spirometry.

Using the simple 20/40 rule in primary care could facilitate the appropriate use of spirometry evaluation and support the diagnosis of COPD in up to $40 \%$ of patients with limited need for further testing. This spirometry testing could be accomplished in the primary care office [28-30] allowing rapid diagnosis and initiation of appropriate COPD management. For the $30 \%$ of individuals

Table 2 Self-report of symptoms and disease - occupational medical evaluation group

\begin{tabular}{lllll}
\hline & Normal $(n=532)$ & Obstructed $(n=815)$ & Restricted $(n=701)$ & Significance \\
\hline Wheeze $[n(\%)]$ & $234(44.0)$ & $593(72.8)$ & $407(58.1)$ & $p<0.001$ \\
Cough $[n(\%)]$ & $285(53.6)$ & $587(72.0)$ & $414(59.1)$ & $p<0.001$ \\
SOB $[n(\%)]$ & $302(56.8)$ & $669(82.1)$ & $501(71.5)$ & $p<0.001$ \\
Sputum $[n(\%)]$ & $195(36.7)$ & $455(55.8)$ & $281(40.1)$ & $p<0.001$ \\
\# of Symptoms [mean (SD)] & $1.9(1.4)$ & $2.8(1.2)$ & $2.3(1.4)$ & $77(11.0)$ \\
Self-reported COPD $[n(\%)]$ & $32(6.0)$ & $304(37.3)$ & $43(6.1)$ & $p<0.001$ \\
Self-reported asthma $[n(\%)]$ & $25(4.7)$ & $135(16.6)$ & $14(2.0)$ & $p<0.001$ \\
Self-reported asthma \& COPD $[n(\%)]$ & $3(0.6)$ & $77(9.5)$ & $144(20.5)$ & $p<0.001$ \\
Self-reported CHD $[n(\%)]$ & $64(12.0)$ & $146(17.9)$ & & $p<0.001$ \\
\hline
\end{tabular}


Table 3 Sensitivity, specificity, positive and negative predictive values for OME group

\begin{tabular}{llllllll}
\hline & $\begin{array}{l}\text { Sensitivity } \\
(\%)\end{array}$ & $\begin{array}{l}\text { Specificity } \\
(\%)\end{array}$ & $\begin{array}{l}\text { Positive } \\
\text { predictive } \\
\text { value (\%) }\end{array}$ & $\begin{array}{l}\text { Negative } \\
\text { predictive } \\
\text { value (\%) }\end{array}$ & $\begin{array}{l}\text { Disease } \\
\text { prevalence } \\
(\%)\end{array}$ & $\begin{array}{l}\text { Positive } \\
\text { Likelihood } \\
\text { Ratio }\end{array}$ & $\begin{array}{l}\text { Negative } \\
\text { Likelihood } \\
\text { Ratio }\end{array}$ \\
\hline For obstruction & $85(84-88)$ & $41(39-43)$ & $40(38-42)$ & $86(84-89)$ & $31(30-33)$ & $1.45(1.39-1.52)$ & $0.34(0.29-0.41)$ \\
$\begin{array}{l}\text { For any spirometry abnormality } \\
\text { (obstruction + restriction) }\end{array}$ & $77(75-79)$ & $50(47-53)$ & $74(72-80)$ & $55(51-58)$ & $65(63-66)$ & $1.55(1.45-1.65)$ & $0.45(0.41-0.50)$ \\
\hline
\end{tabular}

Values listed with (95\% confidence interval) OME - occupational medical evaluation

with a restrictive lung pattern, the addition of lung volumes and perhaps other elements of full pulmonary function testing may be required to determine the accuracy of the restrictive pattern and assess possible associated diagnoses.

Our evaluation of the 20/40 rule confirmed the previously reported over and under diagnosis of COPD within this population. Of those who remembered receiving a COPD or COPD plus asthma diagnosis, $11.3 \%$ had normal spirometry assessment suggesting that a different condition may be causing their symptoms-potential over diagnosis. Conversely, $53.2 \%$ of the individuals with an obstructive pattern did not believe they had received a COPD diagnosis (under diagnosis) likely prohibiting them from receiving any of the therapies known to improve symptom burden or prolong life [31].

\section{Relationship to the literature}

Use of the 20/40 rule goes beyond simply "screening" for risk of COPD and includes the opportunity to evaluate for the presence of restrictive spirometry patterns which may also be seen with COPD or with other conditions in the lungs and other organ systems. Spirometric results from our study groups provide important new data on rates of restrictive spirometry patterns in long-term smokers. Published values for prevalence of a restricted pattern on spirometry in unselected populations vary from 10.3 to $12.3 \%$ [8, 32]. Data from the Multi-Ethnic Study of Atherosclerosis (MESA) [33] showed that among smokers the prevalence of a restricted pattern on spirometry was $10 \%$, increasing by $8 \%$ (95\% confidence interval 3-12\%) for each 10 pack-years smoked. The prevalence of a restricted pattern in MESA was $16 \%$ for the $>20$ pack year cohort, who had a smoking history significantly lower than our OME group (36 pack years, $95 \%$ CI $27-50$ vs $51.9 \pm 27.8$ pack years). Allowing for the additional increase in prevalence of restriction for each pack year smoked found in MESA, the 28.4 and $34.2 \%$ prevalence of restrictive spirometry in our study populations is consistent with the MESA data and provides a useful population estimate in longer-term smokers aged 40 years and older.

Under recognition of lung function abnormalities in smokers is common. But most studies focus on the airflow obstruction reported to occur in up to $50 \%$ of long-term smokers [34] for which under recognition is well documented $[4,16,17]$. However, the underrecognition of a restricted pattern in smokers is less well studied, but is clearly evident from our results which also highlights the potential consequences of underrecognition of both obstructive and restrictive lung function abnormalities. With airflow obstruction, these consequences include under treatment, that may lead to increased exacerbation frequency, symptoms, decreased quality of life, and increased medical costs [35]. Restrictive spirometry patterns are also seen in smoking related conditions such as fibrotic interstitial lung disease, (RBILD or respiratory bronchiolitis with interstitial lung disease) $[10,36]$ muscle weakness [11], heart disease [12], obesity and the metabolic syndrome [13]. A restricted spirometry pattern has been reported to be associated with numerous cigarette and non-cigarette related co-morbidities, including hypertension, type II diabetes, atherosclerosis, cardiovascular disease, and all-cause mortality, in a manner that is statistically independent of confounding variables, such as diabetes, obesity, and

Table 4 Subject characteristics - Algorithm replication population

\begin{tabular}{llll}
\hline & $\begin{array}{l}\text { Normal } \\
n=224\end{array}$ & $\begin{array}{l}\text { Obstructed } \\
n=258\end{array}$ & $n=191$ \\
\hline FEV 1 \% predicted [mean (SD)] & $94.84(9.51)$ & $56.20(13.85)$ & $70.52(10.00)$ \\
FEV $_{1}(\mathrm{~L})( \pm$ SD) & $2.79(0.65)$ & $1.73(0.56)$ & $2.14(0.57)$ \\
Sex (\% male vs. female) & 50 vs. 50 & 71 vs. 29 & 52 vs. 48 \\
Smoke Status (Current vs. Past) & 58 vs. 42 & 65 vs. 35 & 58 vs. 42 \\
BMI [mean (SD)] & $30.06(6.75)$ & $27.01(6.25)$ & $31.65(7.19)$ \\
Age [mean (SD)] & $59.90(9.68)$ & $65.41(10.73)$ & $61.09(9.60)$ \\
Pack years [mean (SD)] & $48.10(43.89)$ & $59.55(36.81)$ & $50.90(46.88)$ \\
\hline
\end{tabular}


smoking history [37-47]. Our data shows that the prevalence of coronary heart disease and all-cause mortality is significantly greater for smokers age $\geq 40$ years with a restricted pattern than for those with normal spirometry. In fact, there was no significant difference in coronary heart disease prevalence and all-cause mortality, between subjects with an obstructed and those with a restricted pattern on spirometry. Under-recognition of both obstruction and restriction in smokers, age $\geq 40$ years, is a common occurrence with significant health consequences.

Other approaches have been developed for selecting patients at high risk of airflow limitation. These include use of questionnaires [48-52], risk prediction models [53] and handheld flow meters [54, 55]. Most questionnaires developed for COPD are related to patient outcomes of quality of life. The COPD population screener (COPD-PS) is a 5 question tool with a positive predictive value of $56.8 \%$ and negative predictive value of $86.4 \%$ [50]. van Schayck et al. [52] and Calverley et al. [56] developed a population-based screening questionnaire for COPD using NHANES III data. Price and coworkers [51] published an 8-item COPD questionnaire in patients with a positive smoking history that included items related to age group, body mass index, pack-year history, and symptoms. Finally, Freeman and colleagues [57] utilized age, cough, dyspnea, and wheezing in a questionnaire to identify patients with COPD in a primary care setting who had a positive smoking history, history of respiratory medication use, or of asthma. The COPD-PS differs from these previous questionnaires because it can be used regardless of history of respiratory problems or smoking and it contains a disease-impact item. Population screeners when used in combination with peak expiratory flow measurement (PEF) however have been shown to add little to PEF alone [54, 58, 59]. A new questionnaire developed by the High Risk-COPD Screening Group is currently undergoing testing in combination with PEF [60]. Preliminary data is impressive [61]. A single published risk prediction model utilizing sex, socioeconomic status and previously recorded asthma diagnosis has performed well in an initial derivation cohort of 480,903 and validation cohort of 247,755 subjects with area under the receiver operating curve of 0.8 [53].

\section{Strengths and limitations}

Limitations in this study include the use of a fixed threshold cut-off for the definition of obstruction $\left(\mathrm{FEV}_{1} / \mathrm{FVC}<\right.$ $70 \%$ ). This fixed ratio threshold has been demonstrated to introduce age related bias [62]. Use of a fixed ratio can result in misclassification in more than $1 / 4^{\text {th }}$ of tests [63] and over diagnosis of airflow obstruction in older subjects [64]. However, the further qualification of $\mathrm{FEV}_{1}<80 \%$ placed on our obstruction definition reduces over diagnosis significantly [65]. FVC and $\mathrm{FEV}_{1}$ were assessed before bronchodilator, allowing the possibility that a portion of the obstructed spirometries might display reversibility, suggestive of a purely asthmatic component, rather than chronic obstructive pulmonary disease [66].

\section{Implications for policy, practice and research}

The goal of this study was to increase use of spirometry in the primary care setting. Only half of primary care providers routinely use spirometry in their practice of medicine [67]. Among primary care physicians spirometry use was associated with agreeing that the data are necessary for accurate diagnosis, and believing that they were trained to perform and interpret the test [68]. In view of these reports and others, we elected to use a simple rule that might increase use of spirometry in the primary care setting without significantly sacrificing accuracy. We wanted to show that use of this simple rule could enhance diagnostic yield that had a clinical impact such as increased risk for CHD and death. Furthermore, it distinguished individuals that would benefit from lung volume measurement. Using the 20/40 rule resulted in detection of an abnormality on spirometry in nearly $70 \%$ of individuals tested.

\section{Conclusion}

We show this simple 20/40 rule, based solely on age and smoking history performs well in predicting pulmonary function abnormalities. Sensitivity of the algorithm was $85 \%$ for an obstructive pattern and $77 \%$ for any abnormality on spirometry. Positive and negative predictive values for any spirometric abnormality were 74 and $55 \%$, respectively. Furthermore, we show that pulmonary function abnormalities, which are often underrecognized, are associated with coronary heart disease and all-cause mortality and might prompt further valuable clinical evaluations. Using an easily applied 20/40 rule based on information that should be available in all medical records, age 40 years or greater and 20 or more years of smoking can simplify the decision of when and with whom to complete spirometry. The results provide clinically significant information for the diagnosis of not only COPD but identification of restrictive lung patterns both of which are associated with increased mortality risk. The 20/40 rule is a simple, sensitive, predictor of lung function abnormalities that are markers for COPD, coronary heart disease and all-cause mortality.

Under diagnosis of chronic lung disease is common. NHANES estimates that $>50 \%$ of individuals with airflow obstruction are undiagnosed [4]. Preliminary data suggests that diagnosis of chronic lung disease is linked to perception and report of symptoms. In a population of screened individuals, matched for FEV1, subjects with a diagnosis of COPD had greater symptom scores than 
those previously unrecognized as COPD [69]. Furthermore, subjects with unrecognized COPD experienced a greater number of postoperative respiratory complications, than subjects diagnosed with COPD, despite similar lung function [70]. These data would suggest that under recognition of symptoms leads to under diagnosis of chronic lung disease. But under recognition of symptoms does not protect patients from the common respiratory complications of surgery that their compromised lung function causes, thus, making a case for selective use of spirometry based on age and smoking history.

\begin{abstract}
Abbreviations
ACOS, asthma-COPD overlap syndrome; ANOVA, Analysis of Variance; BMI, Body mass index; $\mathrm{Cl}$, Confidence interval; $\mathrm{COPD}$, Chronic obstructive pulmonary disease; $\mathrm{FEV}_{1}$, Forced expiratory volume in one second; FVC, Forced vital capacity; GOLD, Global initiative for chronic obstructive lung disease; HR, Hazard ratio; IRB, Wake Forest University Institutional Review Boards; MESA, Multi-Ethnic Study of Atherosclerosis; NHANES, National Health and Nutrition Examination Survey; NICE, National Institute for Clinical Excellence; OR, Odds ratio; PTCA, Percutaneous transluminal coronary angioplasty; RBILD, respiratory bronchiolitis with interstitial lung disease; $\mathrm{SE}$, Standard error
\end{abstract}

\section{Authors' contributions}

$\mathrm{JO}$ and JD were responsible for the original conceptual design. GR was responsible for the technical accuracy of the data included in the study and spirogram inclusion criteria. BY modified the initial format and the data to be included, based on the interests and needs of the primary care practitioner. All authors read and approved the final manuscript.

\section{Competing interests}

Jill A. Ohar - Advisory Boards for BI, AZ, Novartis, \& CSL Behring

Barbara P. Yawn - Advisory Board related to COPD: Novartis and Astra Zeneca Research grant award to my institution - BI

Gregg L. Ruppel - Biomedical Systems - Consulting Fee, Elsevier (Honoraria for textbook), Consultancy - MGC Diagnostics (speaker fees), Consultancy - ndd Medical, Inc. (travel only)

James F. Donohue - None.

\section{Data access $\&$ responsibility}

Dr. Jill Ohar had full access to all the data in the study and takes responsibility for the integrity of the data and the accuracy of the data analysis. All authors have made substantial contributions to all of the following: Conception and design of the study, or acquisition of data, or analysis or interpretation of data; Drafting the article or revising it critically for important intellectual content; Final approval of the version submitted.

\section{Financial support \& disclosure}

Financial support for the research and work described in the manuscript was through Wake Forest Baptist Medical Center Quality Improvement.

\section{Prior presentations}

This manuscript has not been previously published and is not under consideration in the same or substantially similar form in any other peer-reviewed media. We presented some of the data used in this manuscript as posters at the American Thoracic Society International Conferences in 2009 and 2012, in New Orleans, LA and San Francisco, CA, respectively. Some of the data from the OME group was previously published in manuscript form [21].

\section{Author details}

'Department of Internal Medicine, Wake Forest School of Medicine, Medical Center Boulevard, Winston-Salem, NC 27157-1054, USA. ²Department of Research, Olmsted Medical Center, Rochester, MN 55904, USA. ${ }^{3}$ Pulmonary, Critical Care \& Sleep Medicine, Saint Louis University School of Medicine, Saint Louis, MO, USA. ${ }^{4}$ University of North Carolina Chapel Hill, Chapel Hill, NC, USA.
Received: 2 July 2015 Accepted: 23 May 2016

Published online: 04 June 2016

\section{References}

1. Wallace LD, Troy KE. Office-based spirometry for early detection of obstructive lung disease. J Am Acad Nurse Pract. 2006;18(9):414-21.

2. Giuliodori MJ, DiCarlo SE. Simple, inexpensive model spirometer for understanding ventilation volumes. Adv Physiol Educ. 2004;28(1-4):33.

3. Stoller JK. Spirometry: a key diagnostic test in pulmonary medicine. Cleve Clin J Med. 1992;59(1):75-8.

4. Mannino DM, Homa DM, Akinbami LJ, Ford ES, Redd SC. Chronic obstructive pulmonary disease surveillance-United States, 1971-2000. MMWR Surveill Summ. 2002:51(6):1-16.

5. Murphy DE, Panos RJ. Diagnosis of COPD and clinical course in patients with unrecognized airflow limitation. Int J Chron Obstruct Pulmon Dis. 2013:8:199-208.

6. Wilt TJ, Niewoehner D, Kim C, Kane RL, Linabery A, Tacklind J, Macdonald R, Rutks I. Use of spirometry for case finding, diagnosis, and management of chronic obstructive pulmonary disease (COPD). Evid Rep Technol Assess (Summ). 2005;121:1-7.

7. Gentry SE, Hodge RH, Kaiser D, Walker FB, Suratt PM. Pulmonary function testing in a general medical practice. J Community Health. 1983;8(4):263-8.

8. Mannino DM, Holguin F, Pavlin BI, Ferdinands JM. Risk factors for prevalence of and mortality related to restriction on spirometry: findings from the First National Health and Nutrition Examination Survey and follow-up. Int J Tuberc Lung Dis. 2005;9(6):613-21.

9. Decramer M, Janssens W. Chronic obstructive pulmonary disease and comorbidities. Lancet Respir Med. 2013;1(1):73-83.

10. Franks TJ, Galvin JR. Smoking-Related "Interstitial" Lung Disease. Arch Pathol Lab Med. 2015;139(8):974-7. doi:10.5858/arpa.2013-0384-RA. Epub 2014 Nov 21.

11. Kelly JL, Elkin SL, Fluxman J, Polkey MI, Soljak MA, Hopkinson NS. Breathlessness and skeletal muscle weakness in patients undergoing lung health screening in primary care. COPD. 2013;10(1):40-54.

12. Morita S, Mizuno Y, Harada E, Nakagawa H, Morikawa Y, Saito Y, Katoh D, Kashiwagi Y, Yoshimura M, Murohara T, et al. Differences and interactions between risk factors for coronary spasm and atherosclerosis -smoking, aging, inflammation, and blood pressure. Inter Med. 2014;53(23):2663-70.

13. Slagter SN, van Vliet-Ostaptchouk JV, Vonk JM, Boezen HM, Dullaart RP, Kobold AC, Feskens EJ, van Beek AP, van der Klauw MM, Wolffenbuttel BH. Associations between smoking, components of metabolic syndrome and lipoprotein particle size. BMC Med. 2013;11:195.

14. Mannino DM, Sonia Buist A, Vollmer WM. Chronic obstructive pulmonary disease in the older adult: what defines abnormal lung function? Thorax. 2007;62(3):237-41.

15. Mannino DM, Diaz-Guzman E. Interpreting lung function data using $80 \%$ predicted and fixed thresholds identifies patients at increased risk of mortality. Chest. 2012;141(1):73-80.

16. Mapel DW, Robinson SB, Dastani HB, Shah H, Phillips AL, Lydick E. The direct medical costs of undiagnosed chronic obstructive pulmonary disease. Value Health. 2008:11(4):628-36.

17. Mannino DM, Gagnon RC, Petty TL, Lydick E. Obstructive lung disease and low lung function in adults in the United States: data from the National Health and Nutrition Examination Survey, 1988-1994. Arch Intern Med. 2000;160(11):1683-9.

18. Coultas DB, Mapel D, Gagnon R, Lydick E. The health impact of undiagnosed airflow obstruction in a national sample of United States adults. Am J Respir Crit Care Med. 2001;164(3):372-7.

19. From the Global strategy for the diagnosis, management, and prevention of COPD, Global Initiative for Chronic Obstructive Lung Disease (GOLD) [http://www.goldcopd.org]. Accessed 27 May 2016.

20. Qaseem A, Wilt TJ, Weinberger SE, Hanania NA, Criner G, van der Molen T, Marciniuk DD, Denberg T, Schunemann H, Wedzicha W, et al. Diagnosis and management of stable chronic obstructive pulmonary disease: a clinical practice guideline update from the American College of Physicians, American College of Chest Physicians, American Thoracic Society, and European Respiratory Society. Ann Intern Med. 2011;155(3):179-91.

21. Ohar JA, Sadeghnejad A, Meyers DA, Donohue JF, Bleecker ER. Do symptoms predict COPD in smokers? Chest. 2010;137(6):1345-53.

22. Mannino DM, Homa DM, Akinbami L, Moorman JE, Gwynn C, Redd SC. Surveillance for asthma-United States, 1980-1999. MMWR Surveill Summ. 2002:51(1):1-13.

23. Miller MR, Hankinson J, Brusasco V, Burgos F, Casaburi R, Coates A, Crapo R, Enright P, van der Grinten CP, Gustafsson P, et al. Standardisation of spirometry. Eur Respir J. 2005;26(2):319-38. 
24. Hankinson $J$, Odencrantz JR, Fedan KB. Spirometric reference values from a sample of the general U.S. population. Am J Respir Crit Care Med. 1999; 159(1):179-87.

25. Thorax NCG. Chronic obstructive pulmonary disease. National clinical quideline on management of chronic obstructive pulmonary disease in adults in primary and secondary care. Thorax. 2004;59 Suppl 1:1-232.

26. Standardization of Spirometry, 1994 Update. American Thoracic Society. Am J Respir Crit Care Med. 1995;152(3):1107-1136.

27. Braman SS. The chronic obstructive pulmonary disease-asthma overlap syndrome. Allergy Asthma Proc. 2015;36(1):11-8.

28. Licskai CJ, Sands TW, Paolatto L, Nicoletti I, Ferrone M. Spirometry in primary care: an analysis of spirometery test quality in a regional primary care asthma program. Can Respir J. 2012;19(4):249-54.

29. Yawn BP, Enright PL, Lemanske RFJ, Israel E, Pace W, Wollan P, Boushey H. Spirometry can be done in family physicians' offices and alters clinical decisions in management of asthma and COPD. Chest. 2007;132(4):1162-8

30. Llordes M, Jaen A, Almagro P, Heredia JL, Morera J, Soriano JB, Miravitlles M. Prevalence, Risk Factors and Diagnostic Accuracy of COPD Among Smokers in Primary Care. COPD. 2015;12(4):404-12. doi:10.3109/15412555.2014.974736.

31. Maltais F, Dennis N, Chan CK. Rationale for earlier treatment in COPD: a systematic review of published literature in mild-to-moderate COPD. COPD. 2013;10(1):79-103.

32. Aaron SD, Dales RE, Cardinal P. How accurate is spirometry at predicting restrictive pulmonary impairment? Chest. 1999;115(3):869-73.

33. Lederer DJ, Enright PL, Kawut SM, Hoffman EA, Hunninghake G, van Beek EJ, Austin JH, Jiang R, Lovasi GS, Barr RG. Cigarette smoking is associated with subclinical parenchymal lung disease: the Multi-Ethnic Study of Atherosclerosis (MESA)-lung study. Am J Respir Crit Care Med. 2009;180(5):407-14.

34. Lundback $B$, Lindberg $A$, Lindstrom $M$, Ronmark $E$, Jonsson $A C$, Jonsson $E$, Larsson LG, Andersson S, Sandstrom T, Larsson K. Not 15 but $50 \%$ of smokers develop COPD?-Report from the Obstructive Lung Disease in Northern Sweden Studies. Respir Med. 2003:97(2):115-22.

35. Standards for the diagnosis and management of patients with COPD [www.thoracic.org/clinical/copd-guidelines/resources/copddoc.pdf]. Accessed 27 May 2016.

36. Attili AK, Kazerooni EA, Gross BH, Flaherty KR, Myers JL, Martinez FJ. Smoking-related interstitial lung disease: radiologic-clinical-pathologic correlation. Radiographics. 2008:28(5):1383-96. discussion 1396-1388.

37. Leone N, Courbon D, Thomas F, Bean K, Jego B, Leynaert B, Guize L, Zureik M. Lung function impairment and metabolic syndrome: the critical role of abdominal obesity. Am J Respir Crit Care Med. 2009;179(6):509-16.

38. Lange $P$, Nyboe J, Jensen $G$, Schnohr P, Appleyard M. Ventilatory function impairment and risk of cardiovascular death and of fatal or non-fatal myocardial infarction. Eur Respir J. 1991:4(9):1080-7.

39. Ford ES, Mannino DM. Prospective association between lung function and the incidence of diabetes: findings from the National Health and Nutrition Examination Survey Epidemiologic Follow-up Study. Diabetes Care. 2004;27(12):2966-70.

40. Fimognari FL, Pasqualetti P, Moro L, Franco A, Piccirillo G, Pastorelli R, Rossini PM, Incalzi RA. The association between metabolic syndrome and restrictive ventilatory dysfunction in older persons. J Gerontol A Biol Sci Med Sci. 2007;62(7):760-5.

41. Young RP, Hopkins R, Eaton TE. Forced expiratory volume in one second: not just a lung function test but a marker of premature death from all causes. Eur Respir J. 2007;30(4):616-22.

42. Fimognari FL, Scarlata S, Antonelli-Incalzi R. Why are people with "poor lung function" at increased atherothrombotic risk? A critical review with potential therapeutic indications. Curr Vasc Pharmacol. 2010;8(4):573-86.

43. Maclay JD, McAllister DA, Macnee W. Cardiovascular risk in chronic obstructive pulmonary disease. Respirology. 2007;12(5):634-41.

44. Scarlata S, Pedone C, Fimognari FL, Bellia V, Forastiere F, Incalzi RA. Restrictive pulmonary dysfunction at spirometry and mortality in the elderly. Respir Med. 2008:102(9):1349-54.

45. Selby JV, Friedman GD, Quesenberry CPJ. Precursors of essential hypertension: pulmonary function, heart rate, uric acid, serum cholesterol, and other serum chemistries. Am J Epidemiol. 1990;131(6):1017-27.

46. Sin DD, Wu L, Man SF. The relationship between reduced lung function and cardiovascular mortality: a population-based study and a systematic review of the literature. Chest. 2005;127(6):1952-9.

47. Sparrow D, Weiss ST, Vokonas PS, Cupples LA, Ekerdt DJ, Colton T. Forced vital capacity and the risk of hypertension. The Normative Aging Study. Am J Epidemiol. 1988;127(4):734-41.
48. Hanania NA, Mannino DM, Yawn BP, Mapel DW, Martinez FJ, Donohue JF, Kosinski M, Rendas-Baum R, Mintz M, Samuels S, et al. Predicting risk of airflow obstruction in primary care: validation of the lung function questionnaire (LFQ). Respir Med. 2010;104(8):1160-70.

49. Ogura T, Tejima T, Moritani Y, Matuzaki Y, Uchimura K, Aoki M. [The usefulness of COPD questionnaire for screening COPD subjects]. Nihon Kokyuki Gakkai zasshi. 2009;47(11):971-7.

50. Martinez FJ, Raczek AE, Seifer FD, Conoscenti CS, Curtice TG, D'Eletto T, Cote C, Hawkins C, Phillips AL. Development and initial validation of a self-scored COPD Population Screener Questionnaire (COPD-PS). COPD. 2008;5(2):85-95.

51. Price DB, Tinkelman DG, Nordyke RJ, Isonaka S, Halbert RJ. Scoring system and clinical application of COPD diagnostic questionnaires. Chest. 2006;129(6):1531-9.

52. van Schayck CP, Halbert RJ, Nordyke RJ, Isonaka S, Maroni J, Nonikov D. Comparison of existing symptom-based questionnaires for identifying COPD in the general practice setting. Respirology. 2005:10(3):323-33.

53. Kotz D, Simpson CR, Viechtbauer W, van Schayck OC, Sheikh A. Development and validation of a model to predict the 10-year risk of general practitionerrecorded COPD. NPJ Prim Care Respir Med. 2014;24:14011.

54. Mahboub B, Alzaabi A, Soriano JB, Salameh L, Mutairi YA, Yusufali AA, Alsheikh-ali A, Almahmeed W, Haughney J. Case-finding of chronic obstructive pulmonary disease with questionnaire, peak flow measurements and spirometry: a cross-sectional study. BMC Res Notes. 2014;7:241.

55. Jithoo A, Enright PL, Burney P, Buist AS, Bateman ED, Tan WC, Studnicka M, Mejza F, Gillespie S, Vollmer WM. Case-finding options for COPD: results from the Burden of Obstructive Lung Disease study. Eur Respir J. 2013;41(3):548-55.

56. Calverley PM, Nordyke RJ, Halbert RJ, Isonaka S, Nonikov D. Development of a population-based screening questionnaire for COPD. COPD. 2005;2(2):225-32.

57. Freeman D, Nordyke RJ, Isonaka S, Nonikov DV, Maroni JM, Price D, Halbert RJ. Questions for COPD diagnostic screening in a primary care setting. Respir Med. 2005:99(10):1311-8.

58. Ulrik CS, Lokke A, Dahl R, Dollerup J, Hansen G, Cording PH, Andersen KK Early detection of COPD in general practice. Int J Chron Obstruct Pulmon Dis. 2011;6:123-7.

59. Yawn BP, Duvall K, Peabody J, Albers F, lqbal A, Paden H, Zubek VB, Wadland WC. The impact of screening tools on diagnosis of chronic obstructive pulmonary disease in primary care. Am J Prev Med. 2014;47(5):563-75.

60. Leidy NK, Kim K, Bacci ED, Yawn BP, Mannino DM, Thomashow BM, Barr RG, Rennard SI, Houfek JF, Han MK, et al. Identifying cases of undiagnosed, clinically significant COPD in primary care: qualitative insight from patients in the target population. NPJ Prim Care Respir Med. 2015;25:15024.

61. Han MK, Steenrod AW, Bacci ED, Leidy NK, Mannino DM, Thomashow BM, Barr RG, Make BJ, Bowler RP, Rennard SI, Houfek JF, Yawn BP, Meldrum CA Walsh JW, Martinez FJ. Identifying Patients with Undiagnosed COPD in Primary Care Settings: Insight from Screening Tools and Epidemiologic Studies. Chronic Obstr Pulm Dis (Miami). 2015;2(2):103-121. http://www. ncbi.nlm.nih.gov/pubmed/26236776.

62. Miller MR, Quanjer PH, Swanney MP, Ruppel G, Enright PL. Interpreting lung function data using $80 \%$ predicted and fixed thresholds misclassifies more than $20 \%$ of patients. Chest. 2011;139(1):52-9.

63. Guder G, Brenner S, Angermann CE, Ertl G, Held M, Sachs AP, Lammers JW, Zanen $\mathrm{P}$, Hoes AW, Stork S, et al. "GOLD or lower limit of normal definition? A comparison with expert-based diagnosis of chronic obstructive pulmonary disease in a prospective cohort-study". Respir Res. 2012;13(1):13.

64. Medbo A, Melbye H. Lung function testing in the elderly-can we still use FEV1/FVC $<70 \%$ as a criterion of COPD? Respir Med. 2007;101(6):1097-105.

65. Vollmer WM, Gislason T, Burney P, Enright PL, Gulsvik A, Kocabas A, Buist AS Comparison of spirometry criteria for the diagnosis of COPD: results from the BOLD study. Eur Respir J. 2009;34(3):588-97.

66. Perez-Padilla R, Hallal PC, Vazquez-Garcia JC, Muino A, Maquez M, Lopez MV, de Oca MM, Talamo C, Valdivia G, Pertuze J, et al. Impact of bronchodilator use on the prevalence of COPD in population-based samples. COPD. 2007;4(2):113-20.

67. Blain EA, Craig TJ. The use of spirometry in a primary care setting. Int J Gen Med. 2009:2:183-6.

68. O'Dowd LC, Fife D, Tenhave T, Panettieri Jr RA. Attitudes of physicians toward objective measures of airway function in asthma. Am J Med. 2003; 114(5):391-6.

69. Ohar JA, Howard S, Benshoff M, Donohue J. Prevalence and Impact of Unrecognized COPD on Elective Surgery. Eur Respir J. 2012:40(56):3444.

70. Loh CH, Donohue JF, Morgan TM, Collins JB, Ohar JA. Poor Perception of Symptoms and Functional Limitation Affects COPD Diagnosis. Am J Respir Crit Care Med. 2015;191:A4481. 